\title{
EFFECTIVENESS OF SHOCKWAVE THERAPY IN THE TREATMENT OF PLANTAR FASCIITIS
}

\section{EFICÁCIA DA TERAPIA POR ONDAS DE CHOQUE NO TRATAMENTO DE FASCIÍTE PLANTAR}

\author{
Renan Gonçalves leão ${ }^{1}$ (i), Marina Mayumi azuma ${ }^{1}$ (i), Gustavo Henrique Carillo ambrosio ${ }^{1}$ (i), Flavio Faloppa ${ }^{1}$ (i), \\ EDUARDO SHOITI TAKIMOTO ${ }^{1}$ (1), MARCEL JUN SUGAWARA TAMAOKI ${ }^{1}$ (i)
}

1. Universidade Federal de São Paulo, Paulista School of Medicine, Department of Orthopedics and Traumatology, São Paulo, SP, Brazil.

\begin{abstract}
Objective: To evaluate the effectiveness of single-dose focal shockwave therapy in plantar fasciitis treatment. Methods: a primary, prospective study of a series of cases, conducted in the city of São Paulo, Brazil, by the Department of Orthopedics and Traumatology of the Universidade Federal de São Paulo, in Hospital São Paulo. All outcomes were measured at the time of inclusion of the patient in the study and at the post-intervention moments as it follows: three, six and twelve weeks. The VAS, AOFAS and SF-36 scales were applied by teams other than those who performed the SWT. Results: Data from 56 patients were collected during 2017 and 2018. There was improvement of the parameter evaluated $(p<0.005$ and $95 \% \mathrm{Cl})$ in all the periods in which the patients were reevaluated ( 3,6 and 12 weeks), progressive improvement were observed in the three outcomes evaluated. Conclusion: Shock wave therapy was effective for plantar fasciitis treatment according to the proposed protocol considering pain, function and quality of life. Level of Evidence Ic, Case-series Study.
\end{abstract}

Keywords: Fasciitis, Plantar. Shock Wave, figh-fnergy. Quality of Life.

\section{RESUMO}

Objetivo: Avaliar a eficácia da terapia de ondas de choque focais de dose única no tratamento de fasciíte plantar. Métodos: Um estudo primário e prospectivo de série de casos foi realizado na cidade de São Paulo, Brasil, pelo Departamento de Ortopedia e Traumatologia da Universidade Federal de São Paulo, no Hospital São Paulo. Todos os desfechos foram medidos no momento da inclusão do paciente no estudo e nos momentos pós-intervenção da seguinte forma: 3, 6 e 12 semanas. As escalas VAS, AOFAS e SF-36 foram aplicadas por equipes diferentes daquelas que realizaram o tratamento. Resultados: Dados de 56 pacientes foram coletados durante 2017 e 2018. Houve melhora do parâmetro avaliado ( $p<$ 0,005 e /C95\%) em todos os períodos de reavaliação dos pacientes (3, 6 e 12 semanas), sendo observada a melhora progressiva nos três desfechos avaliados. Conclusão: A terapia por ondas de choque foi eficaz no tratamento da fasciíte plantar de acordo com o protocolo proposto, considerando dor, função e qualidade de vida. Nível de evidência Ic, Estudo de série de casos.

Descritores: Fasciíte Plantar. Ondas de Choque, alta energia. Qualidade de vida.

Citation: Leão RG, Azuma MM, Ambrosio GHC, Faloppa F, Takimoto ES, Tamaoki MJS. Effectiveness of shockwave therapy in the treatment of plantar fasciitis. Acta Ortop Bras. [online]. 2020;28(1):7-11. Available from URL: http://www.scielo.br/aob.

\section{INTRODUCTION}

Plantar fasciitis is a condition of pain in the lower heel region, whose most accepted etiology is the one that suggests the condition as a consequence of partial repetitive lesions and chronic inflammation in the plantar aponeurosis, in its insertion in the medial tubercle of the calcaneus. ${ }^{1}$

Plantar fasciitis is the most common cause of pain in the lower heel, with $10 \%$ incidence, being often seen in athletes and military personnel, as well as in sedentary individuals. ${ }^{2,3}$ The risk factors include long time in standing position due to work activity, obesity, use of inappropriate footwear, excessive foot pronation, limited ankle dorsiflexion, and excessive running by unexperienced runners. ${ }^{4,5}$
It is a condition with great socioeconomic impact and it is the most prevalent to receive treatment by specialists. ${ }^{6}$ According to a study by Tong and Furia, more than 2 million patients are treated for plantar fasciitis every year, with a treatment cost estimated between 192 and 376 million dollars a year, in $2007 .^{7}$

The main complaint is pain under the heel that worsens when waking up in the morning or after sitting, which usually gets better after a little walk and at the end of the day with less weight bearing. ${ }^{8}$ Pain in the inferomedial aspect of the calcaneus tuberosity is expected in the physical examination. The symptomatic heel may present erythema and a slight swelling when compared with the contralateral heel.

All authors declare no potential conflict of interest related to this article.

This study was performed at the Department of Orthopedics and Traumatology of the Universidade Federal de São Paulo, Hospital São Paulo. Correspondence: Renan Gonçalves Leão. Avenida Doutor Altino Arantes, 835, apartamento 44. renangleao@gmail.com. 
The diagnosis is made clinically and by exclusion. Radiographs may show calcaneal spurs in $50 \%$ of patients. ${ }^{8}$ Ultrasonography is a low-cost and useful exam to evaluate soft-tissue injuries to the heel. Suggestive findings for the diagnosis of plantar fasciitis include thickening of the plantar fascia greater than $4 \mathrm{~mm}$ and areas of hypoechogenicity. ${ }^{3}$ Magnetic resonance imaging (MRI) is another available test that helps in the evaluation, which has diagnosed plantar fasciitis in $76 \%$ of the sample according to the literature, being also useful for diagnosing other pathological processes in the calcaneus. ${ }^{9}$

Patients rarely undergo surgical treatment. Clinical treatment is recommended for more than $90 \%$ of patients. Different clinical treatments have been reported such as orthoses in shoes (shims and insoles), oral anti-inflammatory agents, local infiltrations of corticosteroids, physiotherapy, and shock wave therapy. However, there is not a consensus about which is the most effective treatment in the literature.

Shock wave therapy - SWT - has been prescribed for the treatment of several musculoskeletal conditions, for being a noninvasive procedure that stimulates tissue and bone regeneration. ${ }^{3,10-13}$

SWT has been prescribed for the treatment of plantar fasciitis; however, there are no prospective clinical studies with a sufficient sample to show its benefits. Furthermore, there is no standardization of the form of treatment and in the measurement of the results, considering pain, function and quality of life. In our sample, a four-dose SWT protocol was described for the treatment of chronic plantar fasciitis. Thus, considering the high prevalence, consequent cost and the controversy over this treatment, our study sought to evaluate the effectiveness of shock wave therapy through questionnaires that assess pain, function and quality of life (VAS, AOFAS and SF-36) and to correlate the outcomes to epidemiological and radiographic data.

The objective is to evaluate the effectiveness of a single application of focal shock wave therapy in plantar fasciitis treatment, considering pain, function and quality of life. The secondary objective is to correlate the improvement of the primary outcomes with epidemiological data.

\section{MATERIALS AND METHODS}

All participants signed the informed consent form. This study was authorized by the Research Ethics Committee of the Universidade Federal de São Paulo, protocol CEP 0231/11.

\section{Statistical Analysis}

Data were analyzed through the ANOVA test. The Pearson correlation test was used to measure the variable interrelation, considering a $0.05(5 \%)$ level of significance and $95 \% \mathrm{Cl}$.

\section{Participants}

The inclusion criteria were: being older than 18 years, of both sexes, patient with unilateral chronic plantar fasciitis diagnosed by clinical, radiographic and ultrasonographic examination; symptoms of heel pain in the region of the proximal insertion of the plantar fascia for more than three weeks; physical examination with pain at palpation of the proximal insertion of the plantar fascia in the inferomedial region of the unilateral calcaneus; ultrasonographic examination of the affected foot showing an inflammatory process in the insertion region of the plantar fascia in the inferior region of the calcaneus; history of three weeks of unsuccessful conservative treatment, including one or the combination of the following therapeutic methods: NSAIDs, resting, heat, ice, ultrasound, massage, orthotics, plaster immobilization, sparking, shoe modification and use of night orthotics.
Exclusion criteria were: treatment with corticosteroid injection of less than 30 days; surgical treatment for prior plantar fasciitis; treatment in progress with anti-inflammatories, active infectious process in the region to be treated, history or documented evidence of autoimmune or peripheral vascular disease, nonpalpable posterior tibial or dorsalis pedis pulses or abnormal capillary filling, history or documented evidence of peripheral neuropathy (tarsal tunnel syndrome, diabetic neuropathy), pregnancy, history or documented evidence of blood clotting disorders (treatment with anticoagulant, excluding aspirin), tumor lesions (primary or secondary tumors), trauma (fracture) or infections (osteomyelitis), use of cardiac pacemaker and allergy or known allergic sensitivity to Xylocaine ${ }^{\circledR}$.

\section{INTERVENTION}

The patient laid down on the stretcher in supine position, without footwear, with ear protectors, with the feet towards the shock wave apparatus and with the application site marked in the medial region towards the lower tubercle of the calcaneus. Asepsis and antisepsis of the foot and ankle were performed, followed by anesthetic block with $5 \mathrm{ml}$ of $2 \%$ lidocaine hydrochloride, posterior tibial nerve, medial retromalleolar region, 15 to 20 minutes before the application of the conductive gel in the heel region, where the device probe was directly positioned.

A single application of 900 pulses follows, with energy around $0.13 \mathrm{~mJ} / \mathrm{mm}^{2}$ with frequency of 4 pulses /s with Evotron (Switch), considered as high energy, greater than $0,12 \mathrm{~mJ} / \mathrm{mm}^{2}{ }^{14}$

Epidemiological data were initially recorded at the first visit, namely: sex, age, BMI, time of pain, laterality, presence of spurs in the radiography. In addition, all patients underwent $\mathrm{X}$-ray examination and ultrasonography to confirm the condition.

\section{Outcomes}

Primary:

- Pain (visual analog scale - VAS)

- Function (AOFAS)

- Quality of life (SF-36)

All outcomes were measured at the time of inclusion of the patient in the study and at the post-intervention moments as it follows: three, six and twelve weeks. Outcomes were measured by physicians or physiotherapists not directly related to the study, all of them capable of measuring the outcomes.

\section{Complication and adverse effects}

Adverse effects, complications and treatment failure were evaluated, considering treatment failure as the need to another intervention besides shockwave therapy, except oral drugs. Another definition was the lack of pain improvement compared with pre intervention pain in subsequent periods (3, 6 and 12 weeks).

\section{RESULTS}

A total of 60 patients were included in the study. Of these, we had 4 patients lost to follow up who did not complete the collection of results. Thus, data from 56 patients were collected during 2017 and 2018: 44 women (78.6\%) and 12 men (21.4\%), with an average age of $49.1+/-2.9$ years and an average time of symptoms of 24.3 months. Average BMI of 28.74 was observed among the selected patients. The presence of calcaneal spur was found in $78.2 \%$ of the sample, as shown in Table 1.

Table 2 shows the results obtained in the Visual Analog Pain Scale (VAS) analysis. 
Table 1. Epidemiologic data.

\begin{tabular}{c|c|c|c|c|c|c|c}
\hline & Mean & Media & Standard Deviation & Min & Max & N & Cl \\
\hline Age & 49.1 & 49.5 & 11 & 27 & 75 & 56 & 2.9 \\
\hline$\Delta$ t symptoms & 24.3 & 12 & 28.8 & 1.5 & 120 & 56 & 7.7 \\
\hline Weight & 76.7 & 75 & 16.1 & 49 & 118 & 56 & 4.2 \\
\hline Height & 1.63 & 1.62 & 0.1 & 1.48 & 1.9 & 56 & 0.03 \\
\hline BMl & 28.74 & 27.65 & 4.98 & 20.08 & 42.82 & 56 & 1.3 \\
\hline
\end{tabular}

Based on the results, we conclude there was a progressive increase in the parameter evaluated in all the periods in which the patients were reevaluated (3, 6 and 12 weeks), as shown in Figure 1.

The functional evaluation obtained with the AOFAS questionnaire showed the results evidenced by Table 3 .

The results obtained showed that the Pre mean (19.5) was higher when compared with all other periods, which had lower and decreasing averages. Thus, the average was 15.1 in Post 3 , versus 13.6 in the Post 6 and 13.1 in the Post 12 (p-values < 0.001, as shown in Table 3). Based on these results, we concluded there was a progressive increase in the AOFAS score.

The SF-36 questionnaire was subdivided into the following parameters in the analysis: Functional capacity (FC), Pain (P), Limitation for physical aspects (LPA), General health status (GHS), Vitality (V), Social aspects (SA), Limitation for emotional aspects (LEA) and Mental health $(\mathrm{MH})$; Statistical difference was observed between

Table 2. Visual analog pain scale analysis.

\begin{tabular}{c|c|c|c|c}
\hline VAS & Pre & Post 3 & Post 6 & Post 12 \\
\hline Mean & 8.31 & 5.9 & 5.74 & 5.08 \\
\hline Median & 8 & 6 & 6 & 5 \\
\hline Standard Deviation & 1.33 & 2.62 & 2.81 & 3.24 \\
\hline $\mathrm{N}$ & 50 & 50 & 50 & 50 \\
\hline $\mathrm{Cl}$ & 0.37 & 0.73 & 0.78 & 0.9 \\
\hline P-value & $<0.001$ & & & \\
\hline
\end{tabular}

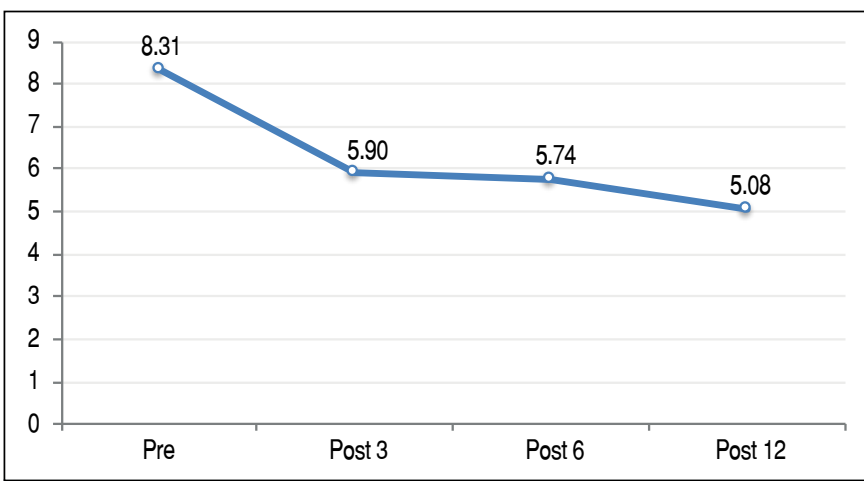

Figure 1. VAS evolution.

Table 3. Aofas analysis.

\begin{tabular}{c|c|c|c|c}
\hline AOFAS & Pre & Post 3 & Post 6 & Post 12 \\
\hline Mean & 19.5 & 15.1 & 13.6 & 13.1 \\
\hline Median & 20 & 14 & 14 & 14 \\
\hline Standard Deviation & 2.7 & 3.4 & 4.9 & 5.7 \\
\hline $\mathrm{N}$ & 56 & 56 & 56 & 56 \\
\hline $\mathrm{Cl}$ & 0.7 & 0.9 & 1.3 & 1.5 \\
\hline P-value & \multicolumn{5}{|c}{$<0.001$} \\
\hline
\end{tabular}

the periods for almost all variables, except general health status and limitation for emotional aspects.

For FC, the averages obtained were: 30.6 in the Pre, 54.0 in the post 3 weeks, 48.4 in the post 6 weeks and 49.4 in the post 12 weeks, in which $p<0.001$. For Pain, the average were: $32.2 ; 46.2 ; 41.1$ and 39.3, with $p=0.003$. For LPA: 9.4; $28.6 ; 21.9$ and 25.4, with $p=0.001$. For GHS: $60.4 ; 62.2 ; 57.7$ and 55.2, with $p=0.353$. For $\mathrm{V}$ : 48.6; $54.0 ; 48.8$ and 48.0, with $p=0.043$. For SA: 50.4; 59.2; 61.6 and 62.1 , with $p=0.015$. For LEA: $20.2 ; 31.5 ; 32.1$ and 32.7 , with $\mathrm{p} 0.129$. And for $\mathrm{MH}: 58.1 ; 63.3 ; 57.1$ and 55.6, with $\mathrm{p}=0.036$ (Figures 2 to 9).

Statistically significant correlations were observed, but all of them have very low values, which make them clinically not significant. The highest correlation occurred between Age and Delta t between pre and post 3 weeks SF36-V with a value of $-40.1 \%$. Since it has a negative value, it indicates that the higher the Age, the lower the value of SF36-V and vice versa. This is a Correlation classified as Regular. No statistically significant differences in sex and quality of life were observed.

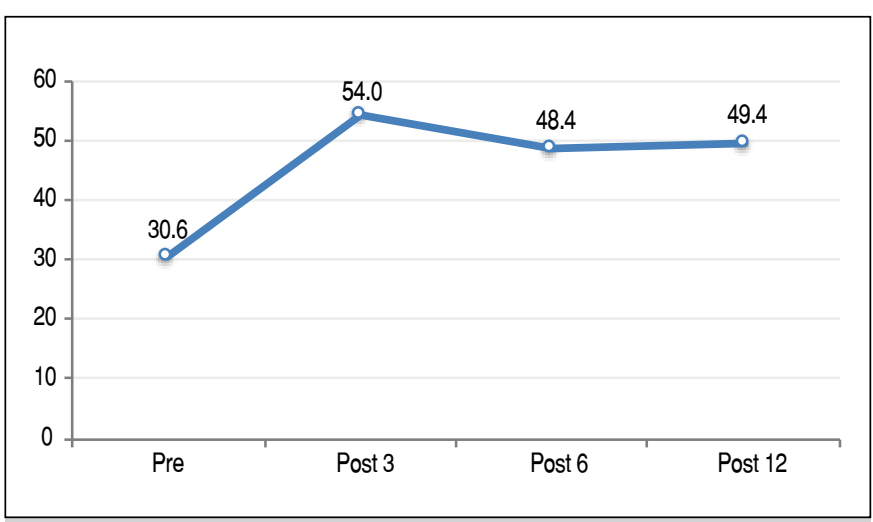

Figure 2. "SF36 - Functional capacity" evolution.

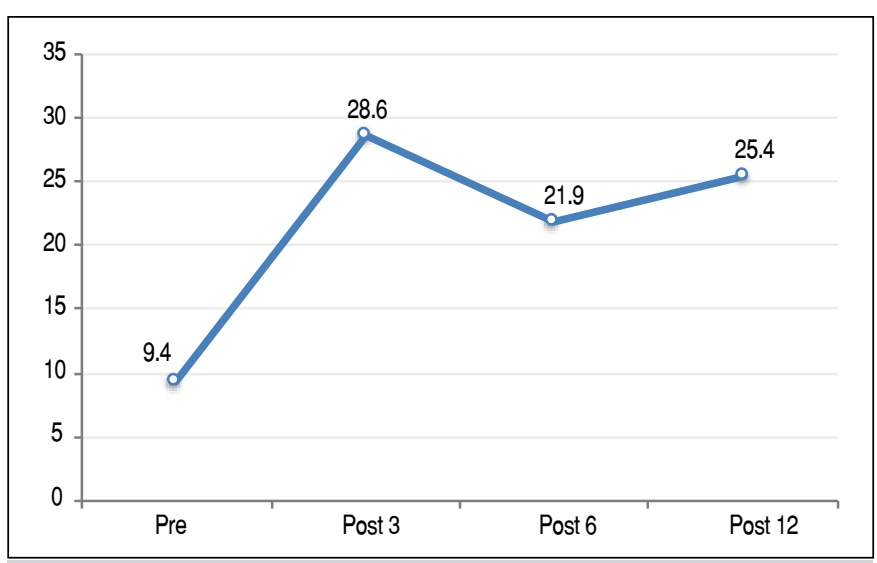

Figure 3. "SF36 - Limitation for physical aspects" evolution. 


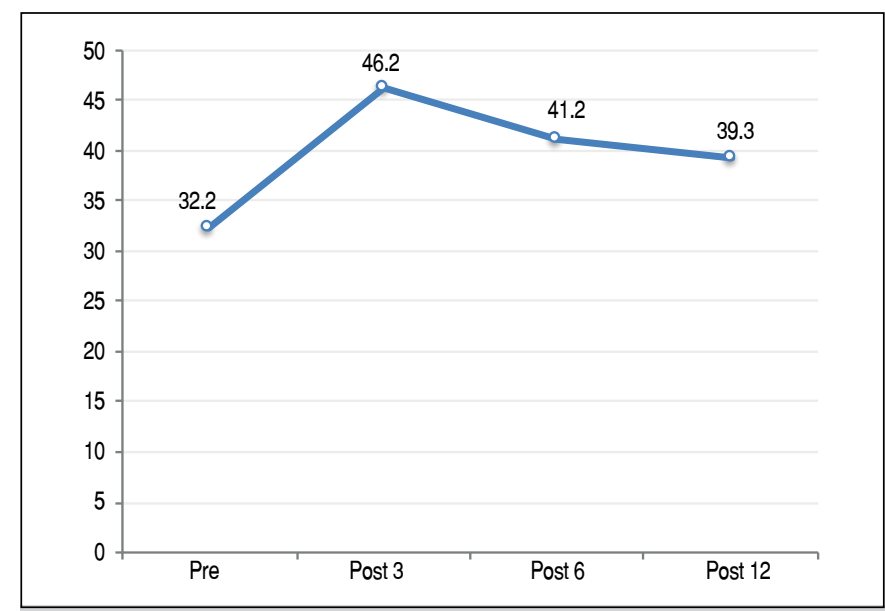

Figure 4. "SF36 - Pain" evolution.

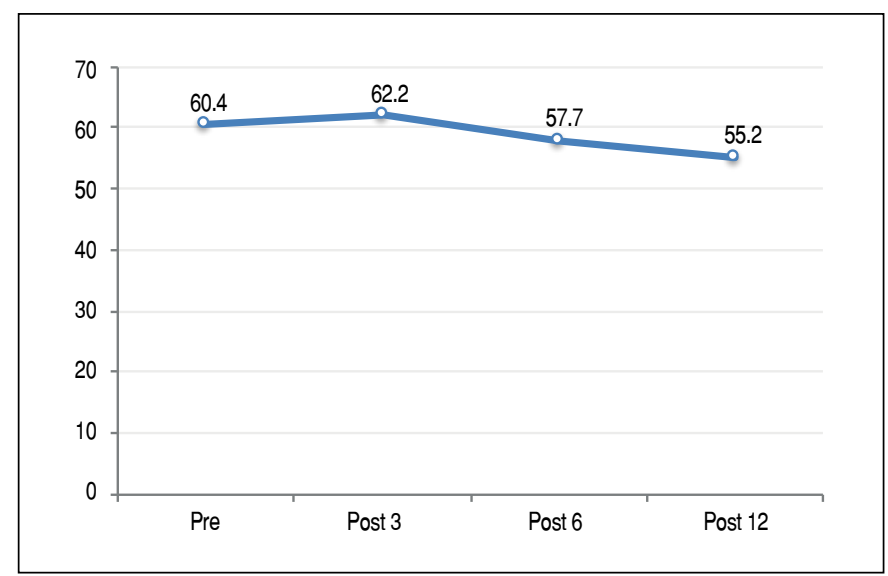

Figure 5. "SF36 - General health status" evolution.

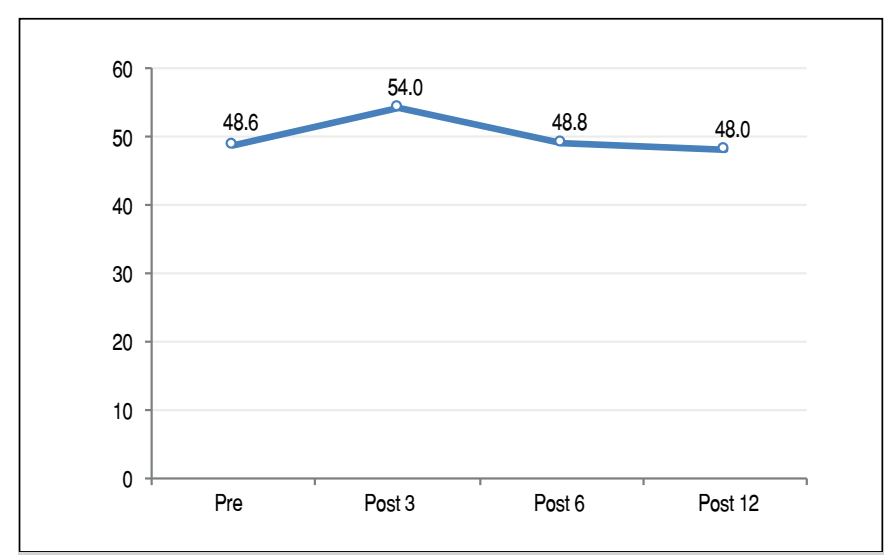

Figure 6. "SF36 - Vitality" evolution.

\section{DISCUSSION}

The shockwave therapy is an alternative to non-surgical treatments (drug and physiotherapy) and less aggressive than surgical treatment for refractory cases. After analyzing the collected data, we obtained a significant improvement in the pain parameter, evaluated by the analog visual scale. In our sample, patients had a quick improvement in pain, seen after 3 weeks and later in the remaining periods of re-evaluation, up to 12 weeks. However, a clinically relevant difference is considered to be a 3-point change in the scale, which was achieved only in the twelfth week of follow-up.

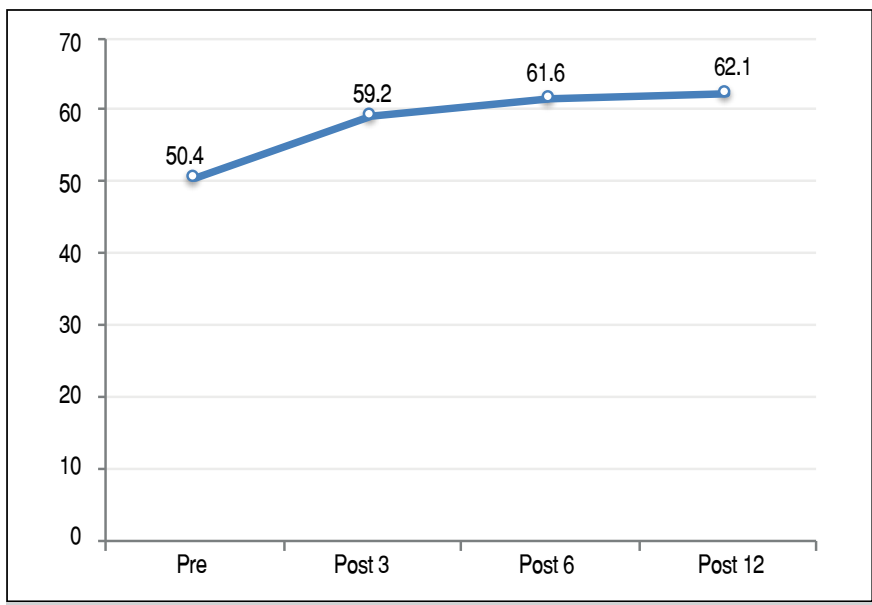

Figure 7. "SF36 - Social aspects" evolution.

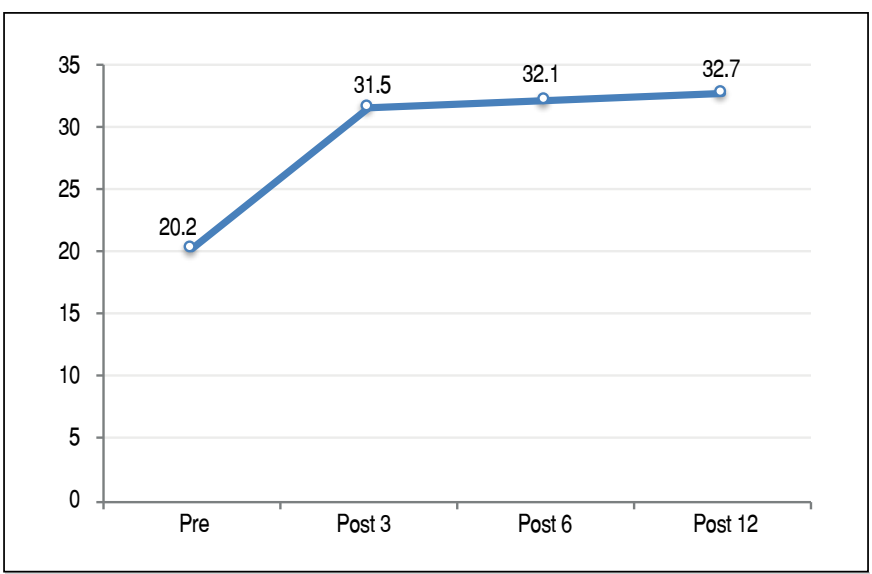

Figure 8. "SF36 - Limitation for emotional aspects" evolution.

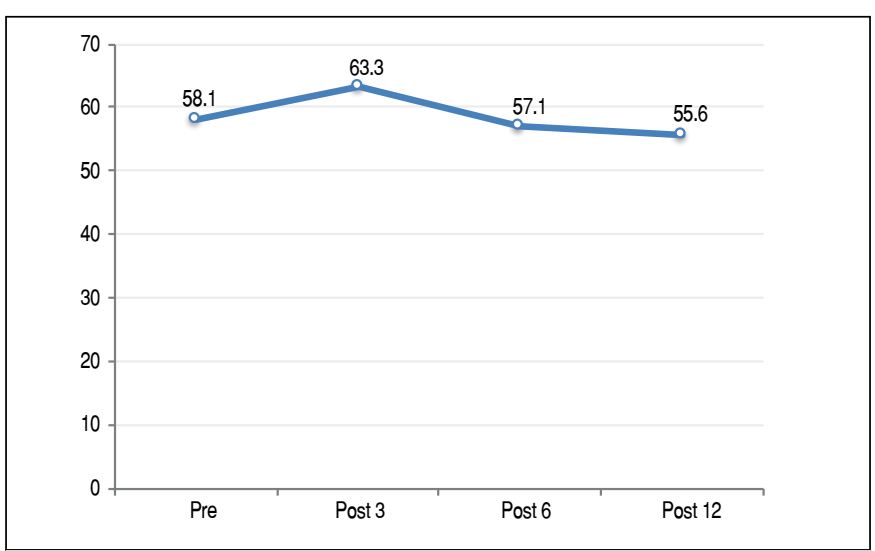

Figure 9. "SF36 - Mental health" evolution.

Our study agrees with the literature, since it shows an improvement in the pain parameter, as found by Gollwitzer et $a . .^{15}$ and Dastgir, ${ }^{16}$ with a significant improvement in VAS at 12 and 24 weeks, respectively. Based on this conclusion, we can affirm the shock wave therapy may be interesting due to the rapid improvement in pain presented, remaining in the later periods of reevaluation. Our study shows an improvement in the AOFAS functional score, agreeing with the results published by Androsoni et al. (2013) ${ }^{11}$, which used the same score and obtained a significant improvement at the end of longer periods of patient reassessment ( 1 month, 3 months and 6 months), 
with patients being subjected to a weekly application for 4 consecutive weeks. However, the study analyzed a small sample of patients, 30 patients (36 feet), who were subjected to the procedure more than once, and the results of quality of life and pain improvement were not evaluated at the end. ${ }^{11}$

In our earlier analysis, we observed a significant increase in the functional score in a shorter period of time, with a single session of SWT, showing that this treatment may positive results in the functionality within three weeks, maintained for up to 12 weeks. The SF-36 score handles several aspects of patients' quality of life and includes: Functional capacity (FC), Pain (P), Limitation for physical aspects (LPA), General health status (GHS), Vitality (V), Social aspects (SA), Limitation for emotional aspects (LEA) and Mental health $(\mathrm{MH})$. Despite the difficulty in applying it due to its extension, the scale has an advantage: the large amount of information of different aspects involving patients' quality of life. In a review in the literature on the treatment of plantar fasciitis with shock wave therapy, no studies were found to evaluate this questionnaire. After the statistical analysis of the results, we could identify an improvement in most of the aspects addressed by the questionnaire after three weeks, revealing a positive short-term impact of SWT on patients' quality of life. As expected, there were no changes in
General Health Status and Limitation for emotional aspects, although most of the patients presented the disease for more than 3 weeks, which could negatively influence these two domains.

Complications of the application of SWT has not been described in the literature. Other studies ${ }^{15}$ also considered the application of shock waves as a safe procedure.

Regarding the multivariate analysis, we found no correlation between the result of the shock wave treatment and the epidemiological data collected, probably due to the small sample for this test. Moreover, we consider the absence of a control group as a limitation of our study. Keeping patients' attendance at the follow-up visits was difficult, which hindered the application of the questionnaires for all patients. The strength of our study is the fact that we showed a series with a number of 60 patients in a prospective study with shock wave treatment with a single application and evaluated the outcome in quality of life.

\section{CONCLUSION}

We conclude that shock wave therapy was effective in plantar fasciitis treatment according to the proposed protocol, which considered pain, function and quality of life. We could not establish a connection between $\mathrm{BMI}$ and the response of the proposed treatment.

AUTHORS' CONTRIBUTIONS: Each author contributed individually and significantly to the development of this article. RGL: article writing, review and data collection (questionnaires). GHCA: data analysis and writing of the article. MMA: data collection (questionnaires), statistical analysis, and review of the article. Data collection (questionnaires), writing of the article. MJST: writing of the article, statistical analysis and intellectual concept of the article and preparation of the entire research project. FF: review of the article and also in any intellectual concept of the article.

\section{REFERENCES}

1. DiGiovanni BF, Nawoczenski DA, Lintal ME, Moore EA, Murray JC, Wilding GE, Baumhauer JF. Tissue-specific plantar fascia-stretching exercise enhances outcomes in patients with chronic heel pain. A prospective, randomized study. J Bone Joint Surg Am. 2003;85(7):1270-7.

2. Riddle DL, Pulisic M, Pidcoe $P$, Johnson RE. Risk factors for plantar fasciitis: a matched case-control study. J Bone Joint Surg Am. 2003;85(5):872-7.

3. Crawford F, Thomson C. Interventions for treating plantar heel pain. Cochrane Database Syst Rev. 2003;(3):CD000416.

4. Scher DL, Belrnont Jr PJ, Bear R, Mountcastle SB, Orr JD, Owens BD. The incidence of plantar fasciitis in the United States military. J Bone Joint Surg Am. 2009;91(12):2867-72.

5. Goff JD, Crawford R. Diagnosis and treatment of plantar fasciitis. Am Fam Physician. 2011;84(6):676-82

6. Al Fischer Associates. 2002 Podiatric Practice Survey. Statistical results. J Am Podiatr Med Assoc. 2003;93(1):67-86.

7. Tong KB, Furia J. Economic burden of plantar fasciitis treatment in the United States. Am J Orthop. 2010;39(5):227-31.

8. League AC. Current concepts review: plantar fasciitis. Foot Ankle Int 2008;29(3):358-66.

9. Chimutengwende-Gordon M, O'Donnell $P$, Singh D. Magnetic resonance imaging in plantar heel pain. Foot Ankle Int. 2010;31(10):865-70.
10. Roehrig GJ, Baumhauer J, DiGiovanni BF, Flemister AS. The role of extracorporeal shock wave on plantar fasciitis. Foot Ankle Clin. 2005;10(4):699-712.

11. Androsoni R, Apostólico Netto A, Macedo RR, Fasolin RP, Boni G, Moreira RFG. Tratamento da fasciíte plantar crônica pela terapia de ondas de choque: avaliação morfológica ultrassonográfica e funcional. Rev Bras Ortop. 2013;48(6):538-44

12. Wolgin M, Cook C, Graham C, Don Mauldin D. Conservative treatment of plantar heel pain: long-term follow-up. Foot Ankle Int. 1994;15(3):97-102.

13. Hammer DS, Adam F, Kreutz A, Kohn D, Seil R. Extracorporeal shock wave therapy (ESWT) in patients with chronic proximal plantar fasciitis: a 2-year follow-up. Foot Ankle Int. 2003;24(11):823-8.

14. Yucel I, Kutay EO, Demiraran Y, Degirmenci E, Kaynak G. Comparison of high-dose extracorporeal shockwave therapy and intralesional corticosteroid injection in the treatment of plantar fasciitis. J Am Podiatr Med Assoc. 2010;100(2):105-10. https://doi.org/10.7547/1000105.

15. Gollwitzer H, Diehl P, von Korff A, Rahlfs VW, Gerdesmeyer L. Extracorporea shock wave therapy for chronic painful heel syndrome: a prospective, double blind, randomized trial assessing the efficacy of a new electromagnetic shock wave device. J Foot Ankle Surg. 2007;46(5):348-57.

16. Dastgir N. Extracorporeal shock wave therapy for treatment of plantar fasciitis J Pak Med Assoc. 2014;64(6):675-8. PMID: 25252488 